Artigo

\title{
As licenciaturas em matemática no período pós-pandemia: o que a extensão universitária sugere?
}

\author{
Mathematics degrees in the post-pandemic period: what does university extension \\ suggest?
}

\author{
Las titulaciones de matemáticas en la pospandémica: ¿qué sugiere la extensión \\ universitaria?
}

\author{
Wanderleya Nara Gonçalves Costa ${ }^{1}$ \\ iD [0000-0002-9352-3171] \\ Admur Severino Pamplona ${ }^{2}$ \\ [0000-0003-1187-3889]
}

\section{Resumo}

A pesquisa inquere sobre permanências na formação inicial de professores de matemática no contexto da extensão universitária. Para isso, considera dois momentos: antes da pandemia e durante ela, na fase de isolamento social. Por um lado, remete a quatro oficinas sobre o uso da matemática na fabricação de artefatos simbólicos de algumas culturas africanas, levadas à cabo em 2019, numa escola de educação básica. Por outro, considera um projeto que diz respeito à elaboração de propostas pedagógicas em regime remoto. Tais propostas tiveram como mote conceitos matemáticos úteis para a compreensão de fenômenos relacionados à pandemia da COVID-19. A pesquisa, qualitativa, descritiva e de cunho reflexivo, tem o objetivo de propor ações para a licenciatura em matemática no período pós-pandemia. $O$ olhar para os dados constantes em relatórios de nove licenciandos membros da equipe foi orientado pelas teorizações do educador Paulo Freire. Defende-se que, em tempos de isolamento social e após ele, é fundamental buscar a humanização, o diálogo e as relações entre os sujeitos do processo educativo escolar. As reflexões suscitadas apontam sugestões que se caracterizam como compromissos éticos, estéticos e políticos, necessários à produção de conhecimentos docentes para uma educação humanizadora.

Palavras-chave: Formação docente. Curricularização da extensão. Pedagogia freireana. Professor de Matemática. Cultura africana.

\begin{abstract}
The research inquires about permanence in the initial formation of mathematics teachers in the context of university extension. For this, it considers two moments: before the pandemic and during it, in the phase of social isolation. On the one hand, it refers to four workshops on the use of mathematics in the manufacture of symbolic artifacts from some African cultures, carried out in 2019, at a basic education school. On the other hand, it considers a project that concerns the elaboration of
\end{abstract}

\footnotetext{
${ }^{1}$ wanderleya.costa@ufmt.br, Doutora em Ensino de Ciências e Matemática, Professora do Instituto de Ciências Exatas e da Terra, do Campus Universitário do Araguaia, da Universidade Federal de Mato Grosso, Pontal do Araguaia/ Mato Grosso/ Brasil.

2 admur.pamplona@ufmt.br, Doutor em Educação, Professor do Instituto de Ciências Exatas e da Terra, do Campus Universitário do Araguaia, da Universidade Federal de Mato Grosso, Pontal do Araguaia/ Mato Grosso/ Brasil.
} 
pedagogical proposals in a remote regime. Such proposals had the motto of mathematical concepts useful for the understanding of phenomena related to the pandemic of COVID-19. The research, qualitative, descriptive and reflective, aims to propose actions for the degree in mathematics in the post-pandemic period. The look at the data contained in the reports of nine graduate staff members was guided by the theories of educator Paulo Freire. It is argued that, in times of social isolation and after it, it is essential to seek humanization, dialogue and relationships between the subjects of the school educational process. The reflections raised suggest suggestions that are characterized as ethical, aesthetic and political commitments, necessary for the production of teaching knowledge for a humanizing education.

Keywords: Teacher training. Extension Curriculum. Freirean pedagogy. Maths teacher. African culture.

\section{Resumen}

La investigación indaga sobre la permanencia en la formación inicial de los profesores de matemáticas en el contexto de la extensión universitaria. Para ello, considera dos momentos: antes de la pandemia y durante la misma, en la fase de aislamiento social. Por un lado, se refiere a cuatro talleres sobre el uso de las matemáticas en la fabricación de artefactos simbólicos de algunas culturas africanas, realizados en $\mathbf{2 0 1 9}$, en una escuela de educación básica. Por otro lado, considera un proyecto que se refiere a la elaboración de propuestas pedagógicas en régimen remoto. Tales propuestas tenían el lema de conceptos matemáticos útiles para la comprensión de fenómenos relacionados con la pandemia de COVID-19. La investigación, cualitativa, descriptiva y reflexiva, tiene como objetivo proponer acciones para la licenciatura en matemáticas en el período pospandémico. La mirada a los datos contenidos en los informes de nueve funcionarios graduados se guió por las teorías del educador Paulo Freire. Se argumenta que, en tiempos de aislamiento social y posteriores a él, es fundamental buscar la humanización, el diálogo y las relaciones entre los sujetos del proceso educativo escolar. Las reflexiones planteadas sugieren sugerencias que se caracterizan como compromisos éticos, estéticos y políticos, necesarios para la producción de conocimientos docentes para una educación humanizadora.

Palabras claves: Formación de profesores. Plan de estudios de extensión. Pedagogía freireana. Profesor de matemáticas. Cultura africana.

\section{Introdução}

Durante a pandemia, as diferenças sociais se acirraram e o número de mortos pela COVID-19 ultrapassou as estimativas mais pessimistas. No Brasil, tornou-se realidade o triste cenário descrito por Martins (2020), no qual foram vistos corpos sem velório "mortos por coronavírus, enterrados talvez em cima dos corpos indígenas e pretos, mortos pela colonização, pela ditadura, e, hoje, pelo neoliberalismo que invade as reservas tradicionais indígenas e quilombolas". (MARTINS, 2020, p.7). Também observamos carreatas contra as medidas de isolamento social, aumento da violência doméstica, feminicídio e recrudescimento de outras formas de agressão, dentre outras atitudes 'desumanas'.

Em paralelo, com o impedimento das atividades presenciais nas escolas, em muitos casos, adotou-se um 'ensino remoto emergencial'. Um tipo de ensino que desloca o professor do seu papel de produtor de conhecimentos, que tira do estudante a condição de sujeito, que desconsidera as relações de afeto, sociabilidade e interação que nesses espaços se estabelecem. Decorre daí a crítica de Santos (2020) e a sua acusação de que: 
Tais iniciativas apresentam uma lógica ética instrumental de maximização de recursos e produtivismo que pode desconsiderar perdas importantes do processo de ensino-aprendizagem, como a formação humana dos estudantes; a participação de profissionais preparados; a complexidade do trabalho educativo. (SANTOS, 2020, p. 917).

Se essa preocupação com uma educação desumanizadora é válida para o momento de isolamento social, não significa que ela não faça sentido para o período pós-pandemia. Ainda que o filósofo italiano Giorgio Agamben estivesse falando de seu país, as ponderações que ele expressa também são adequadas para pensarmos o futuro da educação brasileira:

O que preocupa não é tanto ou não apenas o presente, mas o depois. Assim como as guerras legaram à paz uma série de tecnologias nefastas, do arame farpado às usinas nucleares, também é muito provável que tentaremos continuar, mesmo após a emergência sanitária, os experimentos que os governos não foram capazes de realizar antes: que as universidades e escolas sejam fechadas e as aulas sejam dadas apenas online, que paremos de uma vez por todas para nos encontrarmos e conversarmos por razões políticas ou culturais e trocarmos apenas mensagens digitais, que sempre que possível as máquinas substituam todos os contatos - cada contágio - entre seres humanos. (AGAMBEN, 2020, p. 1, tradução nossa).

Nessas circunstâncias, torna-se especialmente relevante voltar nossa atenção para a formação de professores.

Nos últimos anos, temos pesquisado a constituição da identidade do professor de matemática e, ao fazê-lo, vínhamos investigando a mobilização dos conhecimentos docentes por licenciandos em trabalhos de extensão universitária que ocorrem em escolas de educação básica.

Justifica-se vincular à extensão uma pesquisa sobre identidade docente, uma vez que:

(...) a extensão possui algumas características que se bem exploradas podem vir a contribuir para uma mudança no processo de ensinar e aprender: possuem um arsenal metodológico diferenciado; é feita de encontros entre alunos, professores e comunidades; tem a possibilidade de, neste encontro, incorporar outros saberes, de criar um novo senso comum e de ampliar a capacidade de reflexão sobre as práticas, porque nelas se constituem, ou seja, são constituídas pelas experiências. (CASTRO, 2004, p. 5).

Soma-se às características citadas o reconhecimento do papel formativo que levou à curricularização da extensão, ou creditação (curricular) da extensão, estratégia prevista no Plano Nacional de Educação (PNE) e regulamentada pela Resolução no $7 \mathrm{MEC/CNE/CES,} \mathrm{de}$ 18 de dezembro de 2018 (BRASIL, 2018), que dentre outros estabelece que "as atividades de extensão devem compor, no mínimo, 10\% (dez por cento) do total da carga horária curricular estudantil dos cursos de graduação, as quais deverão fazer parte da matriz curricular dos cursos".

Com a determinação do isolamento social e a interrupção das aulas presenciais, nossos projetos de extensão em execução antes da pandemia também foram descontinuados. Mas nossa investigação vinculada às atividades extensionistas pôde prosseguir quando passamos a tomar os relatórios do projeto 'Educação Matemática e Pandemia' como sendo o corpus da pesquisa. Devido à mudança ocorrida, além das questões que vínhamos abordando, tornou- 
se possível fazer uma análise comparativa entre os trabalhos efetuados nos dois momentos antes e durante a pandemia de COVID-19 - , destacando, em cada um deles, os percalços, as soluções e os sentimentos expressos pelos licenciandos. Esperamos que tal análise ofereça subsídios para orientar a retomada das atividades presenciais, apontando permanências e mudanças necessárias à licenciatura em matemática na sua relação com a extensão universitária.

Nesse texto, ao apresentar os resultados do trabalho, discorremos inicialmente sobre os caminhos teóricos e metodológicos da pesquisa. Na sequência, apresentamos os dados e as análises. De certa forma, a exposição dos dados se aproxima de uma narrativa do vivenciado, pois, como aponta Castro (2004):

No caso da extensão, o que percebemos é que ela produz conhecimento a partir da experiência e assim tem uma capacidade de narrar sobre o seu fazer. O conhecimento narrativo não fecha, ele deixa sempre aberto ao final para a possibilidade de se criar outros finais ou se iniciar outros processos. Assim, a forma de produção da narrativa não pretende ser verdadeira objetivamente, mas ser também subjetiva. (CASTRO, 2004, p. 3-4).

Na narrativa que constituímos a partir da pesquisa realizada, oferecemos sugestões que, talvez, possam contribuir com outras licenciaturas, em especial, licenciaturas em matemática.

\section{Ponderações teóricas e metodológicas}

Nas circunstâncias atuais, frente ao risco da potencialização de uma educação desumanizadora, consideramos apropriado retomar algumas ideias do educador humanista Paulo Freire, para quem, na educação escolar, a centralidade não deveria ser dos conteúdos, mas sim dos sujeitos que estão inseridos na ação educativa.

Em Pedagogia do Oprimido (FREIRE, 1987), Medo e Ousadia: o cotidiano do Professor (FREIRE e SHOR, 1986), Educação e Mudança (2001), Educação como Prática de Liberdade (FREIRE, 1992) e Pedagogia da Autonomia (FREIRE, 2011), dentre outros, Paulo Freire nos fala sobre a importância de se constituir estratégias voltadas para a formação de pessoas comprometidas com a cidadania e a responsabilidade social, que valorizem os saberes, o diálogo e que estejam fundamentadas no inacabamento do ser humano.

Na obra de Freire (2011), a alegria e a esperança são partes integrantes de todo processo educativo. Por isso, segundo ele, ao ensinar, o professor precisa ter alegria e esperança: a alegria de que "[...] professor e aluno juntos, podem aprender, ensinar, inquietarse e resistir aos obstáculos com alegria [...], na verdade, a esperança faz parte da natureza humana." (FREIRE, 2011, p. 70). Freire (2011) nos fala da boniteza do processo de aprendizagem, boniteza esta que se expressa nos sentimentos de esperança, solidariedade e ética. Ele diz que, ao cultivar a boniteza da aprendizagem junto aos discentes, o professor promove a valorização da expressão, da comunicação e do conhecimento, constituindo sensibilidade para o exercício da cidadania e da convivência social.

De fato, a Pedagogia Freiriana aponta fatores que ele considera essenciais à formação docente, nomeadamente: a relação teoria-prática, o saber escutar, o diálogo, a educação problematizadora, o inacabamento do ser humano, a alegria e a esperança, a ética e a estética; o reconhecimento de que só há docência com discência. Para Paulo Freire, o 
educador precisa auxiliar o educando a superar a consciência ingênua e ir em direção à consciência crítica, por meio da análise de problemas com argumentos consistentes, mobilizando o gosto pela pesquisa, pelo novo e pelo diálogo. Nessas condições, em cursos de licenciatura, deve-se constituir estratégias que contemplem a ideia de que a "[...] reflexão crítica sobre a prática se torna uma exigência da relação Teoria-Prática" (FREIRE, 2011, p. 24).

Freire (1980) ofereceu-nos também uma reflexão conceitual importante para a extensão universitária, defendendo-a como uma situação educativa que ocorre por meio de um processo dialógico. Na extensão universitária assim concebida, educadores e educandos assumem o papel de sujeitos cognoscentes, mediatizados pelo objeto que ambos desejam conhecer. Foi por essa via, da extensão universitária assim compreendida, pensando a educação matemática de modo problematizador, que propusemos o projeto de extensão 'Educação Matemática e Pandemia', com execução de abril a novembro de 2020.

Por outro lado, ao considerarmos o período anterior à pandemia, tomamos como foco de análise a última etapa de um projeto de extensão coordenado por nós em 2019. Estamos nos referindo ao apoio a uma escola estadual situada na cidade de Barra do Garças/MT, na organização das reflexões e das comemorações relativas ao Dia Nacional da Consciência Negra, como uma das ações do projeto de extensão 'LEMA nas escolas'.

Por meio do Laboratório de Educação Matemática Profa. Adarcy Miguez (LEMA) oferecemos apoio a professores de educação básica para a execução de oficinas, cursos e eventos nas escolas - daí o nome do nosso projeto. No processo de via dupla, as escolas contribuem com a formação inicial de professores e tornam-se contextos de nossas pesquisas.

Em setembro de 2019, fomos procurados por um professor de matemática que solicitou nosso assessoramento no evento que estava sendo organizado em sua escola. A ideia era propor ações que, de algum modo, pudessem contribuir para a desconstrução da imagem estereotipada acerca dos saberes africanos, aumentando a autoestima e estimulando a criatividade dos estudantes daquela instituição. Em resposta à solicitação, juntamente com o professor de Matemática e a professora de História, apoiados teoricamente na Etnomatemática e metodologicamente na Resolução de Problemas, elaboramos e executamos quatro oficinas e auxiliamos na organização das comemorações de culminância do evento.

Sucintamente, as oficinas podem ser descritas como sendo de:

- Tecidos africanos: para o 6 ano, reprodução de padrões de tecidos dos povos Akan, em papel craft, por meio do qual foram estudadas isometrias.

- Máscaras Africanas: 70 ano, reprodução de máscaras africanas do povo Bwa, em papelão. Os conteúdos abordados foram: medidas, número de ouro, figuras geométricas e escalas.

- As casas dos Ndebele: 8o ano, construção de uma maquete com miniaturas das casas Ndebeles. Conceitos matemáticos explorados: medidas, figuras geométricas planas e introdução ao estudo do cilindro e do cone.

- Jogos africanos: a borboleta de Moçambique - 9o ano, confecção e ornamentação dos tabuleiros do jogo moçambicano. Ângulos e Teorema de Talles foram os conteúdos abordados.

No planejamento de cada oficina, nas semanas que antecederam o evento, auxiliados pela professora orientadora, trabalharam dois professores em formação inicial, sendo que pelo menos um deles já havia cursado a disciplina de Estágio I. As oficinas ocorreram entre os dias 12 e 22 de novembro de 2019, de tal forma que foi possível estabelecer um sistema de 
trabalho que permitiu alocar, em cada sala de aula, no desenvolvimento da atividade, um mínimo de quatro licenciandos - os dois que planejaram as atividades e pelo menos mais dois auxiliares. Além deles, um professor lotado na escola esteve presente em cada oficina. Alguns dos licenciandos atuavam como bolsistas do PET - Programa de Educação Tutorial, no grupo PET Matemática Araguaia, da UFMT.

Por sua vez, o projeto 'Educação Matemática e Pandemia' foi concebido a partir da percepção de que: a) muitos estudos e informações acerca da descrição e da previsão da disseminação de pandemias se constituem ou se amparam em modelos matemáticos; b) com frequência, informações estatísticas não são bem compreendidas pela população; c) por vezes, tem ocorrido, durante a pandemia de COVID-19, certa manipulação de dados, que causa grave impacto na medida em que potencializa não apenas a desinformação, mas também políticas de exclusão social e até mesmo necropolíticas (MBEMBE, 2018).

Nessas circunstâncias, entendemos que a abordagem escolar da matemática poderia ser um instrumento no combate à COVID-19 ao contribuir para que estudantes e suas famílias efetuassem análises quantitativas e qualitativas sobre a doença. Isto posto, firmamos como objetivos específicos do projeto de extensão 'Educação Matemática e Pandemia': a) a elaboração de ferramentas que pudessem apoiar professores de matemática, do Ensino Fundamental, Médio e também dos semestres iniciais de Ensino Superior, a ilustrarem em suas aulas o uso de conceitos matemáticos para a compreensão crítica dos dados relacionados à pandemia de COVID-19; b) contribuir com os licenciandos preparando-os para compreender e aplicar as metodologias de ensino que têm sido propostas no campo da Educação Matemática.

Após os primeiros meses de trabalho na execução do referido projeto (de abril a julho), um dos resultados foi a elaboração de quatro propostas pedagógicas, formuladas por duplas de licenciandos auxiliadas pelos seus orientadores. As propostas pedagógicas que elaboramos foram denominadas de Matemática e Pandemia I, II, III e IV. Cada uma delas está associada, de forma mais contundente, a uma metodologia de ensino da Educação Matemática Resolução de Problemas, Modelagem Matemática, Educação Matemática Crítica e História da Matemática.

Cada proposta pedagógica contém infográficos, textos e atividades que permitem discutir, no contexto das metodologias de ensino escolhidas, a aplicação de conteúdos matemáticos para a compreensão dos problemas cotidianos, com foco na pandemia causada pelo novo coronavírus. Contudo, não acreditamos que caiba ao professor apenas reproduzir conhecimentos. Logo, não oferecemos um material pronto e acabado, com respostas, ou mesmo com possibilidades de respostas únicas, pois tivemos especial cuidado de não silenciar as epistemologias próprias do espaço profissional do professor da educação básica.

Em ambos os projetos de extensão - 'LEMA nas escolas' e 'Educação Matemática e Pandemia' - os professores em formação inicial membros da equipe escreveram relatórios individuais. Na pesquisa, esses documentos foram identificados como CA, DA, FA, JO, LO, GE, MAR, MAT ou MI. Foram dos relatórios que extraímos os dados da etapa de investigação que ora apresentamos.

\section{Análise de duas experiências}

Ao esmiuçar os dados, adotamos as perspectivas analíticas oferecidas pela Análise de Conteúdo de Bardin (1977) e acolhemos categorias emergentes - compreendidas como aquelas elaboradas com base nos dados, as que surgem a partir de ligações entre as diversas 
variáveis presentes. Então, do olhar para os dados, emergiram as categorias: a) a insegurança do professor iniciante; b) contratempos com equipamentos, materiais e instalações físicas; c) os estudantes e suas dificuldades com a matemática; d) o olhar para o Outro, o estudante 'diferente'; e) os sentimentos e a alegria de ser professor.

A seguir, apresentamos nossas análises acerca de cada uma dessas categorias.

\subsection{A insegurança do professor iniciante}

Freire (1997) chama atenção para o fato de que a entrada na profissão docente é marcada por sentimentos diversos, entre os quais está a insegurança, "sobretudo se a professora ou o professor, mais do que se pensar inseguro, está realmente inseguro, e se sente tocado pelo medo de não ser capaz de conduzir os trabalhos e de contornar as dificuldades" (p.44). Por sua vez, Silveira (2015, p. 367) nos lembra que a "iniciação à docência tem como base o protagonismo dos professores mais experientes (docentes das instituições de ensino superior e das escolas) na formação dos aspirantes à docência".

De fato, no início de ambos os projetos aqui analisados, os licenciandos precisaram lidar com sua insegurança, de modo a superá-la para efetuar o trabalho - no que contaram com o auxílio de professores experientes. Vejamos como eles se expressaram a esse respeito.

Licenciando DA: O intuito era trabalhar conteúdos matemáticos aliados a reflexões relacionadas à Consciência Negra. Inicialmente achei desafiadora a união dos assuntos, porém com as sugestões da professora orientadora de trabalhar com os padrões presentes nos tecidos dos povos Akan, construir a oficina não foi algo complicado.

(Relatório de participação no projeto presencial, 2019).

Licencianda JO: Com essa pandemia tudo ficou meio conturbado, mas já estamos melhorando nosso caminho de trabalho. Como exemplo temos nossa primeira reunião em videoconferência. No início foi meio difícil para mim, porque não estava costumada a lidar com tais tecnologias, mas hoje em dia acho que todos nós já temos facilidade com a variedade tecnológica. Também tem sido um grande desafio fazer as pesquisas com o uso das tecnologias digitais, porém estou aprendendo a usar vários tipos de tecnologias (...). Como o trabalho tem sido feito em dupla, temos que fazer uso de tecnologias como videochamada, Whatzapp, para o melhor desenvolvimento do trabalho, não sabia como utilizar algumas ferramentas e através do trabalho estou aprendendo a utilizar.

(Relatórios de participação no projeto remoto, 2020).

Nos dois momentos - antes da pandemia e durante ela, no período de isolamento social - as dificuldades iniciais foram enfrentadas a partir do apoio dos professores formadores e, no primeiro momento, os licenciandos puderam contar também com o apoio dos professores da escola na qual a ação foi realizada.

Assim, no primeiro momento, de elaboração e execução das oficinas, a ação da professora da universidade levou à realização de discussões sobre interdisciplinaridade, transdisciplinaridade e sobre o uso de metodologias de ensino apropriadas. Também encaminhou estudos sobre Etnomatemática e orientou o aprimoramento das atividades. $\mathrm{Na}$ escola, o professor de matemática contribuiu com a ambientação dos licenciandos e auxiliou tanto na gestão das atividades, quanto na lida com os estudantes foco da ação.

No segundo momento, isto é, no projeto executado durante a pandemia, o professor da universidade precisou, antes que fosse possível a reunião por videoconferência, enviar por 
e-mail um tutorial para os licenciandos e, no decorrer da reunião, demonstrar solidariedade e empatia e indicar as leituras iniciais para o estudo. Entretanto, no decorrer do desenvolvimento das atividades, por vezes, os licenciandos sentiram falta de análises mais balizadas sobre a adequação das tarefas para os estudantes dos anos/séries aos quais estavam destinadas, indicando a importância da ação complementar do professor da educação básica.

As duas situações - o desenvolvimento do projeto presencial e do projeto remoto confirmaram que o sentimento de insegurança do licenciando precisa ser reconhecido e que o apoio de professores experientes é importante para ultrapassar os primeiros obstáculos de ação profissional. A orientação dos profissionais experientes, tanto da universidade quanto da escola, incide sobre aspectos diversos e nos parece que a permanência de ambos os tipos de contribuição é importante para o período pós-pandemia. Sobretudo, é importante que isso ocorra por meio de ações intencionais e previamente acordadas ente os profissionais docentes.

\subsection{Contratempos com equipamentos, materiais e instalações físicas}

Em ambos os projetos - o presencial e o desenvolvido em atividades remotas -, após contornar a sua insegurança, os professores iniciantes precisaram enfrentar percalços relacionados à falta de equipamentos e à inadequação de materiais e/ou de instalações físicas.

Licenciando DA: ... montamos o notebook e o projetor, a sala não contava com tomadas próximas ao local de montagem, no entanto um estudante rapidamente solucionou o problema, pegando emprestado uma extensão na sala dos professores.

Licenciando MI: Infelizmente, quando estávamos ainda explicando com os slides, ocorreu um imprevisto, pois tivemos que entregar o datashow para outra professora. Isso ocorreu porque ela já havia reservado com antecedência e aquele era o único projetor de propriedade da escola. Então arrumamos uma solução: colocamos as regras no quadro para que os estudantes acompanhassem no quadro a construção. No final da aula até fomos elogiados pela professora que estava na sala junto conosco, pois ela achou muito bom que nós arrumamos uma solução muito rápida para o problema do datashow.

Licenciando FA: Os alunos se mostraram muito empolgados, porém como as máscaras foram feitas de papelão, tivemos alguns problemas. A grande maioria dos papelões eram duros, dificultando o corte dos moldes das máscaras, pois foram disponibilizadas tesouras pequenas para o manuseio dos alunos. Tivemos que pegar uma tesoura grande para que nós mesmos pudéssemos fazer os cortes e auxiliá-los.

(Relatórios de participação no projeto presencial, 2019).

Portanto, nas ações presenciais, os contratempos foram: falta de tomada no local de instalação do equipamento, escassez de datashow e de tesouras adequadas para cortar o papelão duro. Os professores em formação inicial conseguiram resolver os percalços usando estratégias diversas: trocando o meio de exposição do conteúdo, solicitando empréstimo de tesouras mais afiadas e tomando para si parte da tarefa de cortar o papelão, para não colocar os estudantes em perigo. Assim, não houve prejuízo na execução da atividade.

Percebe-se que os licenciandos, ultrapassadas as primeiras inseguranças, tiveram condições de agir com autonomia, discernimento e responsabilidade. As dificuldades com as quais se confrontaram os levaram a perceber a carência da escola, o que nos parece 
importante para o conhecimento do contexto nos quais irão trabalhar. No futuro póspandemia, é improvável que nos deparemos com uma valorização da educação escolar que dê conta de afastar a carência financeira das escolas públicas brasileiras. Assim, nas ações de extensão que se realizam nesses espaços, embora seja possível contornar a questão da carência de modo imediatista - levando emprestado do laboratório universitário datashow, extensão elétrica, tesouras e outros - , os obstáculos podem servir de argumento para se discutir a dotação orçamentária para a educação pública e também a participação na gestão financeira escolar. Nesse sentido, observemos que a descentralização administrativa e pedagógica e a desconcentração da aplicação de recursos para os sistemas de ensino público têm sido pautas que assumem grande relevância nas reivindicações docentes.

Para Freire (2001, p. 127), a participação de professores e da comunidade extraescolar na gestão escolar é fundamental e, como explicitou, "Participar é discutir, é ter voz, ganhandoa, na política educacional das escolas, na organização de seus orçamentos". Freire propôs ainda uma reflexão sobre o compromisso da gestão democrática na assunção dos princípios de descentralização e de participação quando esteve à frente da Secretaria de Educação do município de São Paulo, tendo afirmado: "Para nós, descentralização e participação dizem respeito ao ato de decidir. $O$ equívoco que mais frequentemente se comete em relação a essas questões é descentralizar a execução das tarefas e manter as decisões centralizadas". (Secretaria Municipal de Educação de São Paulo, 1992, p. 66)

Apesar da importância de se discutir, nas licenciaturas, a questão da gestão administrativa e financeira das escolas, no curso que atuamos, o tema não está presente nas ementas das disciplinas. Mas, como nos ensinou Freire:

(...) a melhor maneira que a gente tem de fazer possível amanhã alguma coisa que não é possível ser feita hoje, é fazer hoje aquilo que hoje pode ser feito. Mas se eu não fizer hoje o que hoje pode ser feito e tentar fazer hoje o que não pode ser feito, dificilmente eu faço amanhã o que hoje também não pude fazer. (FREIRE, 2011, p. 12).

Assim, devido à certa dificuldade/morosidade para fazer alterações nas ementas das disciplinas do curso, bem como à centralidade formativa das ações de extensão, conforme regulamentado pela Resolução no $7 \mathrm{MEC/CNE/CES,} \mathrm{de} 18$ de dezembro de 2018, há que se pensar em incluir reflexões/avaliações a respeito da gestão administrativa e financeira da escola dentro das próprias ações extensionistas, de modo a aumentar sua contribuição na formação inicial docente.

Observemos agora como as dificuldades relacionadas à falta de materiais e de equipamentos, bem como à inadequação de instalações físicas, interferiram no projeto desenvolvido durante o período da pandemia de COVID-19:

... o grau de dificuldade é extremante diferente do que participar das atividades presenciais e estudar na biblioteca com salas específicas sem barulho que ajudam na melhor concentração para o estudo. A realidade muda quando o estudo é em casa, pelas várias distrações, por ter que fazer outras atividades de casa, ou cumprir ordem, ou por esquecer de fazer algo. Os problemas familiares são ótimos para a dispersão e a falta de concentração em alguns horários do dia. MAT

Tem sido um grande desafio para mim fazer as pesquisas através do uso das tecnologias digitais, porém estou aprendendo usar vários tipos de tecnologias, o que tem agregado muito na obtenção de conhecimento, pois como o trabalho tem sido feito em dupla, temos que fazer 
uso de tecnologias como vídeo chamada (...) não sabia como utilizar algumas ferramentas $e$ através do trabalho estou aprendendo a utilizar essas tecnologias. No futuro (...) nós como professores estaremos mais preparados para lidar com o uso das tecnologias, $e$ as metodologias para o ensino da matemática que dependem delas. JO

Em minha opinião, é muito difícil conciliar o trabalho [remoto] com a família, pois com essa pandemia não estou morando mais no Pontal [a cidade de Pontal do Araguaia/MT, sede do Curso], apenas continuo no aluguel. Estou com minha família na roça, onde tem muito trabalho e a internet é muito difícil. Tem ainda o meu filho que requer também uma atenção maior. MI (Relatórios de participação no projeto remoto, 2020).

Assim, os problemas verificados na execução do projeto em regime remoto revelam que a presença física na universidade, em bibliotecas e laboratórios adequadamente equipados, continuam sendo fundamentais para que os licenciandos se organizem para os estudos. Logo, as reivindicações em favor das instituições públicas de ensino superior se mostram como uma permanência importante no período pós-pandemia. Entretanto, os desafios e as soluções encontradas também nos indicaram que, no período pós pandemia, nas licenciaturas em matemática, além de nos preocuparmos com a discussão de softwares e ambientes virtuais específicos para o ensino e a aprendizagem da disciplina, é importante problematizar as opções de comunicação digital entre professores e estudantes, bem como alguns parâmetros de conduta ético-profissional para o seu uso.

\subsection{Os estudantes e suas dificuldades com a matemática}

Principalmente o primeiro excerto colocado a seguir indicia a preocupação do professor em formação inicial no sentido de promover uma educação matemática problematizadora, no qual o conhecimento matemático vá se constituindo a partir do diálogo, sem que se permita a permanência do "corpo indeciso e acomodado", como dizia Paulo Freire.

Alguns grupos apresentaram dificuldades em escolher os símbolos [parte dos padrões Adinkra, para a oficina inspirada em tecidos do povo Akan] e reproduzi-los no papel, neste momento tivemos que ajudar os estudantes, sempre propondo soluções. Por exemplo, alguns encontravam dificuldades em encontrar a quantidade de desenhos que deveriam fazer, então propus o seguinte: medir com a régua o tamanho do papel e em seguida com a calculadora do celular dividir esse tamanho pela quantidade de desenhos desejada, ou seja, não dei a solução diretamente ensinei ferramentas para os estudantes pensarem. Com os valores calculados, foi a hora de dividir o papel, aparentemente eles não entenderam como aplicar esses valores, foi então que tracei retas paralelas e comecei a dividi-lo, logo parei deixando que eles finalizassem seguindo os primeiros passos que apresentei. DA

Então começamos a confeç̧ão [das maquetes das casas Ndebeles na turma do 8o A], montagem do cone e do cilindro, ensinando-lhes como usar o compasso, mas tiveram certa dificuldade em manusear o mesmo, pois muitos deles não sabiam que era e muito menos como usá-Io. [No 8 B] Distribuímos os materiais e demos as instruções para confecção e montagem do cone e do cilindro, a turma também teve dificuldade em manusear o compasso. Então fizemos como na outra turma, passando de carteira em carteira dos que precisavam $e$ ajudamos a usar pela primeira vez o instrumento. MAR 
Duas alunas não estavam interessadas, faziam as coisas de qualquer modo. No momento, pensei simplesmente que elas estavam com preguiça, mas depois, percebi que eu deveria ter conversado mais com elas, para saber o motivo do descaso. Talvez elas não tivessem entendido o que era para fazer e estavam com dificuldade. Esse episódio me fez refletir: nunca poderei desistir de um aluno, eles podem estar passando por situações inimagináveis, e enquanto eles tiverem em sala, ou até mesmo fora dela, terei que fazer o que tenho ao meu alcance para ajudá-los na construção de seus próprios conhecimentos. GE

(Relatórios de participação no projeto presencial, 2019)

Sobre as dificuldades com o manuseio do compasso, bem como do uso da régua como auxiliar para a realização das tarefas, cabe destacar que os avanços na área de informática têm permitido que instrumentos como a régua e o compasso sejam substituídos por softwares. No entanto, a utilização dos recursos computacionais não atinge a totalidade das escolas - como de fato era o caso da escola onde realizamos o projeto em pauta. Além disso, entendemos que o uso de instrumentos manuais para construções geométricas propicia aos estudantes uma aprendizagem mais efetiva, que inclui a compreensão de problemas e de soluções cotidianas e também da própria história da Matemática.

Em particular, Zuin (2001), pontua que os softwares possuem um papel importante na construção do pensamento geométrico, mas que as construções realizadas com régua e compasso devem ser anteriores ao uso do software, pois permitirão um melhor entendimento dos passos das construções realizadas no ambiente computacional, reforçarão os conceitos e proporcionarão a constituição de uma lógica acerca da sequência a ser usada nas construções. Em vista do exposto, entendemos que o uso de diferentes instrumentos para o ensino da geometria - incluindo, portanto, tanto softwares quanto instrumentos manuais - deve permanecer constante nas ações que ocorrerão pós-pandemia.

De todo modo, observa-se, no último fragmento anteriormente colocado, a reflexão da licencianda sobre a necessidade de alterar seu olhar para os estudantes. Desse modo, a concepção freiriana de que "não há docência sem discência", isto é, que cabe o professor 'olhar para o estudante' e buscar o diálogo que contribua para que ele construa conhecimentos, esteve presente na ação dos licenciandos. Essa presença pôde ser observada não apenas nas atividades presenciais - como indiciam os trechos dos relatórios que destacamos-, mas também a preocupação com possíveis dificuldades matemáticas estudantes se manteve nas atividades desenvolvidas no período de isolamento social:

No preenchimento da tabela, o cálculo do número que representa a diminuição dos indivíduos saudáveis ao longo de oito semanas, já na sétima semana toda a população está infectada e tanto a sétima semana quanto a oitava semana apresentariam um número negativo. Como explicar isso aos estudantes, se 'num bairro não há número negativo de pessoas'? Vou ter que 'abstrair', falar um número pode ser aceitável como resposta da aplicação do modelo matemático, mas não encontrar correspondência exata na situação real. MI

(Relatório de participação no projeto remoto, 2020).

O olhar atento para o estudante, não só para as dificuldades matemáticas, mas também para seu comportamento frente às propostas pedagógicas, em ambos os projetos 'LEMA nas escolas' e 'Educação Matemática e Pandemia' - foi algo que se manteve, ainda que se efetuasse de forma diversa. 


\subsection{O olhar para o Outro, o estudante 'diferente'}

Como revelam os fragmentos dispostos a seguir, o trabalho no primeiro projeto colocou em evidência diversidades étnicas e culturais; enquanto o segundo expôs, de modo mais contundente, as diferenças entre classes sociais.

Na sala havia alunos indígenas, eles pareciam um pouco perdidos e o professor Rogério sugeriu que eles fizessem desenhos de sua cultura nos padrões dos 'tecidos'. MAR

Em um dos grupos havia um estudante indígena, inicialmente o mesmo estava tímido perante o grupo, neste momento minha colega interferiu chamando o estudante para a produção do material, com essa interferência o mesmo participou então da construção, desenhando e pintando, um dos símbolos e utilizando isometria. DA

Um momento que me chamou atenção foi quando foi pedido para se sentarem em dupla, todos estavam sentando com os colegas, e um aluno indígena não se movia para sentar-se com ninguém, e ninguém demostrava que queria fazer dupla com ele. Chegou um momento, quando a maioria dos alunos já estavam com as duplas formadas, que sobrou uma aluna, e aí ela disse que iria sentar com esse aluno, porém demostrou que estava fazendo isso contra sua vontade. Também no momento da execução da atividade, percebi que em alguns momentos esse aluno indígena se sentia intimidado com a sua colega, cheguei até imaginar que ele não tinha domínio da língua portuguesa, foi quando questionei uma pessoa que me disse que ele fala sim a língua portuguesa. Em alguns momentos tivemos que ir até lá e incentivar ele a ajudar a colega, nisso percebi que ele começou a se interagir e ajudar na execução da atividade. $F A$

(Relatórios de participação no projeto presencial, 2019).

É válido explicar que o curso de licenciatura no qual atuamos está situado na conurbação de três cidades: Pontal do Araguaia/MT, Barra do Garças/MT e Aragarças/GO e que a história da região é marcada pelo convívio de não índios com os povos indígenas Bororo, Karajá e A'uwe Xavante. Assim, existe um grande fluxo de índios das aldeias, principalmente para a cidade de Barra do Garças; onde estão localizados órgãos que centralizam as demandas dos povos indígenas na região do médio Araguaia.

Após cursarem os anos iniciais nas escolas situadas nas aldeias, muitos índios adolescentes, principalmente a'uwe xavantes, vêm estudar em escolas urbanas; por isso, nas quatro oficinas oferecidas, sempre esteve presente pelo menos um estudante indígena. Destarte, a educação básica em Barra do Garças/MT é marcada pela diversidade etnocultural e torna-se importante que o professor em formação inicial vivencie situações que o levem a perceber, refletir e trabalhar com as distintas culturas em contato. Afinal, como pontuou (FREIRE, 2011), a relação professor-aluno deve ser pensada como o encontro pedagógico que permite a experiência intersubjetiva necessária ao aprendizado da competência relacional.

A pedagogia freiriana é caracterizada pelo profundo respeito à identidade cultural do estudante, pela sua linguagem, gênero, classe, etnia, orientação sexual e desenvolvimento cognitivo. De modo contundente, Paulo Freire nos fala da importância de se respeitar a cultura do estudante. Segundo ele, (FREIRE, 1976, p.81) a educação escolar "enquanto a ação cultural para a libertação se caracteriza pelo diálogo, "somo selo" do ato de conhecimento, a ação cultural para a domesticação procura embotar as consciências. A primeira problematiza; a segunda "sloganiza". 
Como é possível observar a partir dos extratos dos relatórios dos licenciandos anteriormente colocados, as ações de extensão presenciais nas escolas da região, geralmente, permitem que os professores em formação inicial vivenciem situações que implicam o reconhecimento da diversidade cultural. A convivência com a pluralidade, com a diferença, permite que exercitem a tolerância e o respeito, algo que é fundamental para que o diálogo se estabeleça, pois:

Aceitar e respeitar a diferença é uma dessas virtudes sem o que a escuta não pode se dar. Se discrimino o menino ou a menina pobre, a menina ou $o$ menino negro, o menino índio (...) não posso evidentemente escutá-los e se não os escuto, não posso falar com eles, mas a eles, de cima para baixo. Sobretudo, me proíbo de entendê-los. (FREIRE, 2011, p. 56).

Mas certa preocupação com possíveis diferenças entre os estudantes também surgiu nas atividades em período de pandemia, embora fossem de outra ordem, conforme explicita o trecho abaixo:

Temos os alunos. Estes têm acesso a internet? As condições socioeconômicas são favoráveis para se estudar em casa? $O$ ensino de aulas remotas será suficiente para que eles aprendam o conteúdo? (...) também é preciso analisar o quanto a desigualdade social e vários fatores sociais estão ligados a disseminação do vírus e à mortalidade que causa, muito além da idade, mais ligada a desigualdade socioeconômica. MAT

(Relatórios de participação no projeto remoto, 2020).

Como pontuamos anteriormente, nas atividades de extensão durante o isolamento social, ocorreu certo 'apagamento' do sujeito/estudante, que não permite/dificulta ao professor - relegado ao papel de mero executor/aplicador de aulas previamente preparadas - tomar atitudes baseadas na percepção das diversidades culturais. Por outro lado, as desigualdades sociais passaram a ocupar com mais intensidade as reflexões dos licenciandos.

Parece-nos que, no olhar para o 'outro', o estudante 'diferente', no período póspandemia, as duas preocupações precisam ser mantidas, afinal, segundo Gomes:

A diversidade, entendida como construção histórica, social, cultural e política das diferenças, realiza-se em meio às relações de poder e ao crescimento das desigualdades e da crise econômica que se acentuam no contexto nacional e internacional. Não se pode negar, nesse debate, os efeitos da desigualdade socioeconômica sobre toda a sociedade e, em especial, sobre os coletivos sociais considerados diversos. Portanto, a análise sobre a trama desigualdades e diversidade deverá ser realizada levando em consideração a sua interrelação com alguns fatores, tais como: os desafios da articulação entre políticas de igualdade e políticas de identidade ou de reconhecimento da diferença no contexto nacional e internacional, a necessária reinvenção do Estado rumo à emancipação social, o acirramento da pobreza e a desigual distribuição de renda da população, os atuais avanços e desafios dos setores populares e dos movimentos sociais em relação ao acesso à educação, à moradia, ao trabalho, à saúde e aos bens culturais, bem como os impactos da relação entre igualdade, desigualdades e diversidade nas políticas públicas. (GOMES, 2012, p. 1).

Nesse contexto, cabe lembrar que, atualmente, na Educação Matemática, sobretudo a Etnomatemática e a Educação Matemática Crítica, oferecem aos educadores o instrumental 
teórico adequado para abordar as diversidades e as desigualdades. Há que se observar que tais perspectivas de pesquisa e de ensino da matemática estão umbilicalmente relacionadas às teorizações de Paulo Freire. Por sua vez, as obras de Freire apontam que, na educação escolar, é fundamental que sejam cultivados os diálogos, as relações humanas, o acolhimento, a sensibilidade e a amorosidade, a boniteza do ensinar e do aprender, de modo que esta se constitua "humanista e humanizadora".

Desse modo, na observância desta categoria de análise, percebe-se que, no período pós-pandemia, precisamos buscar, com ainda mais afinco, a humanização, o diálogo e as relações entre os sujeitos do processo educativo escolar. Precisamos, portanto, reservar espaços na licenciatura para questionar acerca de diferenças etnoculturais, sociais e outras e, a partir daí, gerar novos caminhos tanto para a extensão, quanto para as discussões nas disciplinas.

\subsection{Os sentimentos, a alegria de ser professor}

É fato que, na convivência no espaço escolar, também são tecidos relações e sentimentos que escapam das lógicas dos conteúdos. Nessas circunstâncias, colocando em destaque a beleza da atividade docente da qual Freire nos fala, observemos os extratos dispostos a seguir. Contudo, importa ressaltar que, ao contrário do que ocorreu nas categorias anteriores nas quais buscamos trazer narrativas de licenciandos diferentes, a respeito da realização de oficinas diferentes, nessa categoria, intencionalmente, escolhemos dois fragmentos escritos por uma mesma licencianda.

Foi muito bom participarmos ativamente das atividades com os alunos. Pudemos perceber a relação professor aluno, principalmente com o professor de matemática. (...) Transcorreu tudo maravilhosamente bem, pois praticamente todos os profissionais da escola trataram-nos muito bem, e os alunos também, pelo menos eu me senti muito importante, feliz por ter escolhido esta profissão de professora. MI

(Relatório de participação no projeto presencial, 2019).

Nossas tarefas têm sido muito produtivas e gratificantes quando prontas, pois estão proporcionando grandes conhecimentos sobre a forma de trabalhar com as metodologias de ensino de matemática e sobre a BNCC. MI

(Relatório de participação no projeto remoto, 2020).

Desse modo, em ambas as situações - nas atividades presenciais e nas realizadas à distância -a professora em formação inicial revela o bem-estar produzido por um trabalho bem avaliado, visto que, conforme Jesus (2007):

O conceito de bem-estar docente pode ser traduzido pela motivação e a realização do professor, em virtude do conjunto de competências (resiliência) e de estratégias (coping) que este desenvolve para conseguir fazer frente às exigências e dificuldades profissionais, superando-as e otimizando o seu próprio funcionamento. (JESUS, 2007, p. 26).

Entretanto, num momento a licencianda fala em ter-se sentido 'feliz', noutro ela fala que as 'tarefas foram produtivas e gratificantes'. Mas foi a relação prazerosa estabelecida com os estudantes e os profissionais da escola que revelaram a ela a boniteza de docência.

Freire enfatiza que a busca do 'ser mais' não pode realizar-se no isolamento. Com certeza, uma das preocupações de Freire era a de que a educação não servisse somente para 
desenvolver competências e habilidades de modo a capacitar os estudantes para sua inserção na economia de uma sociedade; ao contrário, segundo seu pensamento, a educação precisa ser humanizadora. Note-se que foram as relações humanas, o acolhimento, a sensibilidade e a amorosidade que levaram a licencianda citada a confirmar sua opção pela docência, e não apenas o trabalho bem realizado, o conhecimento constituído. Isso nos leva a concluir que o aspecto "humanista e humanizador" de atividade docente deve ser uma permanência fundamental nos projetos extensionistas vinculados à formação inicial de professores.

\section{Considerações finais}

Ao longo desse texto, analisamos atividades de extensão que ocorreram em dois momentos - anterior à pandemia e durante o período. A relevância desse tipo de análise se ancora no fato de que a extensão universitária permite que se redesenhe práticas para a formação inicial de professores, ampliando as possibilidades para encontros com estudantes da educação básica, com professores em exercício e com outros sujeitos do espaço escolar. Nas licenciaturas, as atividades de extensão também favorecem o conhecimento prático acerca de condicionantes culturais, sociais, políticos e econômicos, dentre outros colocados para o exercício da profissão docente.

Em vista disto, neste trabalho, tomando a extensão universitária como um dos lócus para a construção do conhecimento profissional docente na licenciatura e as teorizações de Paulo Freire como referências, questionamos: o que a extensão universitária sugere para as licenciaturas em matemática no período pós pandemia?

As análises apontaram que os aspectos abaixo elencados deverão ser mantidos quando traçarmos novos rumos para a formação inicial de professores:

a) Ações conjuntas, contínuas e acordadas entre os professores orientadores (da universidade) e dos professores supervisores (da educação básica) no apoio aos licenciandos nas suas atividades docentes. Essa postura dos professores experientes pode ser fundamental para auxiliar os professores em formação inicial a ultrapassar os momentos de insegurança.

b) A discussão, na licenciatura, da dotação orçamentária para a educação pública e da participação da comunidade na gestão financeira das escolas - favorecendo não só a prática democrática, mas também a compreensão acerca dos percalços pelos quais a educação pública brasileira vem passando.

c) A intensificação do uso de softwares e ambientes virtuais específicos para o ensino e a aprendizagem da matemática deverá ser aliada a reflexões sobre a comunicação digital entre professores e estudantes, bem como alguns parâmetros de conduta ético-profissional para o seu uso.

d) Devem ser engendradas oportunidades para discutir o papel dos professores frente às diferenças etnoculturais, sociais e outras que se manifestam no ambiente escolar. É importante manter a articulação com o outro e a escuta atenta que auxiliarão os licenciandos a compreender que múltiplos condicionantes afetam a aprendizagem escolar. Quanto à observância desse aspecto, ele ocorreu de forma diversa nos dois projetos/momentos, antes da pandemia e durante ela. Para além das questões cognitivas e mesmo das dificuldades dos estudantes no uso de instrumentos de apoio ao aprendizado da geometria, no primeiro momento, os licenciandos estiveram atentos às diferenças culturais e, no segundo momento, seu olhar foi direcionado para as desigualdades sociais. Entendemos que, no espaço escolar, 
tanto as dificuldades, quanto as diversidades e as desigualdades precisam ser observadas pelos licenciandos, o que requer a sua problematização nas licenciaturas.

e) A competência teórico-metodológica do professor deve estar associada à sua afetividade. No primeiro momento foco de nossas análises, nos deparamos com a felicidade promovida pelos encontros. No segundo momento, do ensino remoto, percebemos apenas a satisfação com o desenvolvimento de habilidades e competências técnicas para a docência. De fato, o conhecimento gerado em regime remoto não evidenciou a boniteza da ação docente, as relações de emoção não mantiveram sua potência. Nesse sentido, nas licenciaturas, deve ser enfatizado o aspecto afetivo não apenas relacionando-o aos estudantes da educação básica, mas também aos professores.

Em suma, concluímos que, na formação inicial de professores, no período pós pandemia, deve haver um cuidado especial com o estabelecimento de relacionamentos interpessoais, com a assunção de compromissos éticos, estéticos e políticos, necessários à produção de conhecimentos docentes para uma educação humanizadora.

Assim, no retorno às atividades presenciais nas universidades e nas escolas, cabe reinventar o futuro afastando-o com veemência da normalidade que o filósofo Agamben (2020) esboçou, conforme citamos no início deste texto. Então, na sequência da investigação sobre a constituição da identidade dos professores de matemática, ao analisarmos os relatos dos licenciandos, será importante verificar quais narrativas emergirão, se voltadas para uma educação humanizadora e humanizante, pautada por compromissos éticos, estéticos e políticos, ou se....

\section{Referências}

AGAMBEN, Giorgio. Chiarimenti. Quodlibet, Una você. Macerata. Publicado em 17 de março de 2020. Disponível em: https://www.quodlibet.it/giorgio-agamben-chiarimenti. Acesso em: 16 set. 2020.

BARDIN, Laurence. Análise de conteúdo. Lisboa: Edições 70, 1977.

BRASIL. Ministério da Educação. Resolução CNE/CES/MEC no7, de 18 de dezembro de 2018. Estabelece as Diretrizes para a Extensão na Educação Superior Brasileira e regimenta o disposto na Meta 12.7 da Lei no 13.005/2014, que aprova o Plano Nacional de Educação - PNE 2014-2024e dá outras providências. Brasília, 2018. Disponível em: http://www.in.gov.br/materia//asset_publisher/Kujrw0TZC2Mb/content/id/55877808. Acesso em 14/11/2019.

CASTRO, Luciana Maria Cerqueira. A universidade, a extensão universitária e a produção de conhecimentos emancipadores. In: REUNIÃO ANUAL DA ANPED, 27. Caxambu, 2004. Anais da 27 reunião da ANPEd. Caxambu: ANPEd, 2004. Disponível em: http://27reuniao.anped.org.br/gt11/t1111.pdf. Acesso em: 08 set. 2020.

FREIRE, Paulo. Ação cultural para a liberdade e outros escritos. Rio de Janeiro: Paz e Terra, 1976.

FREIRE, Paulo. Educação e mudança. 24. Ed. São Paulo: Paz e Terra, 2001

FREIRE, Paulo. Extensão ou comunicação? 5. ed. Rio de Janeiro: Paz e Terra, 1980. 
FREIRE, Paulo. Pedagogia da Autonomia: saberes necessários à prática educativa. 43. ed. São Paulo: Paz e Terra, 2011.

FREIRE, Paulo. Pedagogia do Oprimido. 11. ed. Rio de Janeiro: Paz e Terra, 1987.

FREIRE, Paulo. Professora sim, tia não: cartas a quem ousa ensinar. São Paulo: Olho d'água, 1997.

FREIRE, Paulo; SHOR, Ira. Medo e ousadia: o cotidiano do professor. 10.ed. Rio de Janeiro: Editora Paz e Terra, 1986.

GOMES, Nilma Lino. Desigualdades e diversidade na educação. Campinha, 2012.

JESUS, Saul N. Professor sem stress: realização profissional e bem-estar docente. Porto Alegre: Mediação, 2007.

MARTINS, Ricardo Evandro Santos. O vírus neoliberal no Brasil e a polêmica com Giorgio Agamben. Voluntas, Santa Maria, v.11, e20, p. 1-8, jul. 2020. Disponível em: https://periodicos.ufsm.br/voluntas/article/view/44019. Acesso em: 26 ago. 2020.

MBEMBE, Achille. Necropolítica. 3 ed. São Paulo: n-1 edições, 2018.

SANTOS, Lais Silveira. Dilemas morais da gestão pública brasileira no enfrentamento da pandemia do novo coronavírus. Rev. Adm. Pública, Rio de Janeiro, v. 54, n. 4, p. 909-922, ago. 2020. Disponível em: <http://www.scielo.br/scielo.php?script=sci_arttext\&pid=S0034-

76122020000400909\&lng=pt\&nrm=iso>. Acesso em: 28 ago. 2020.

SECRETARIA MUNICIPAL DE EDUCAÇÃO DE SÃO PAULO. Planejamento. Instrumento de mobilização popular. São Paulo: Prefeitura do Município de São Paulo, 1992.

SILVEIRA, Helder Eterno da. Mas, afinal: o que é iniciação à docência? Atos de Pesquisa em Educação. Blumenau, v. 10, n.2, p.354-368, mai./ago. 2015. Disponível em: https://proxy.furb.br/ojs/index.php/atosdepesquisa/article/view/4704/3046. Acesso em 15 set. 2020.

ZUIN, Elenice de Souza Lodron. Da régua e do compasso: as construções geométricas como um saber escolar no Brasil. Dissertação apresentada ao Programa de Pós-Graduação da Faculdade de Educação da Universidade Federal de Minas Gerais, Belo Horizonte - MG 2001. Disponível em: https://repositorio.ufmg.br/bitstream/1843/FAEC-85DGQB/1/zuin_elenice_disserta_nopw.pdf. Acesso em: 17 set. 2020. 